\title{
Understanding the interaction between demonstrative deixis and descriptive content
}

\author{
Entendendo a interação entre a dêixis \\ demonstrativa e o conteúdo descritivo
}

Lovania Roehrig Teixeira

Sergio de Moura Menuzzi

Resumo

Neste artigo discutimos o papel do conteúdo descritivo nos usos dêiticos dos demonstrativos. Nosso foco está em casos em que as descrições demonstrativas são licenciadas por conteúdo descritivo adicional, tornando dispensáveis elementos indexicais como as demonstrações e a saliência contextual. Com base em tais casos, argumentamos que: (i) o componente indexical das descrições demonstrativas deve fazer referência a subsituações da situação de fala, como proposto por Wolter (2006); (ii) a dêixis demonstrativa, porque se refere a essas subsituações, pode ser imprecisa; nesses casos, é necessário computar composicionalmente o conteúdo descritivo das descrições demonstrativas. Isso constitui um argumento contra a ideia de que o componente indexical dos demonstrativos se refere diretamente ao referente da descrição demonstrativa, como na chamada "teoria da referência direta” de Kaplan (1989), e como em outras abordagens (NUNBERG 1993, 2004; KING, 2001; ELBOURNE, 2008, entre outros).

Palavras-chave: demonstrativos, dêixis, semântica de situações, referência direta.

\footnotetext{
* Doutora em Letras - UFRGS

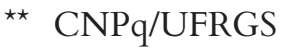




\section{Abstract}

In this paper we discuss the role of descriptive content in deictic uses of demonstratives. Our focus is on cases where descriptive descriptions are licensed for additional descriptive content, making indexical elements such as demonstrations and contextual salience unnecessary. On the basis of these cases, we argue that: (i) the indexical component of the descriptive descriptions must refer to subsituations of the speech situation, as proposed by Wolter (2006); (ii) because it refers to these subsituations, the demonstrative deixis may be imprecise; in such cases, it is necessary to compute the descriptive content of the demonstrative descriptions compositionally. This is an argument against the idea that the indexical component of the demonstratives directly refers to the referent of the demonstrative description, as in the so-called "direct reference theory" proposed by Kaplan (1989), as well as in others approaches (NUNBERG, 1993, 2004; KING, 2001; ELBOURNE, 2008, among others).

Keywords: demonstratives, deixis, situation semantics, direct reference. 
L. ROEHRING

TEIXIERA \& S. DE

M. MenuzZI

Understanding

the interaction

between

demonstrative

deixis and

descriptive content

\section{Introduction}

The basic facts we want to discuss in this paper are the following: deictic uses of demonstrative descriptions (DEMs) usually require a demonstration to be felicitous, as shown by the contrast between (1a) and (1b) below; but, under some circumstances, additional descriptive content makes the demonstration unnecessary, as shown by the contrast between (1b) and (1c):

(1) Context: in a restaurant, the manager and a waiter on the bar are facing the customers in the room. The manager whispers to the waiter:

a. [pointing to couple 2:]

That couple wants a cesar sallad.

b. [with no pointing:]

\# That couple wants a cesar sallad.

c. [with no pointing:]

That couple next to the window wants a cesar sallad.

Revista Letras, Curitiba, UFPR, n. 96 , pp.509-529, jul./dez. 2017. ISSN 2236-0999 (versão eletrônica)

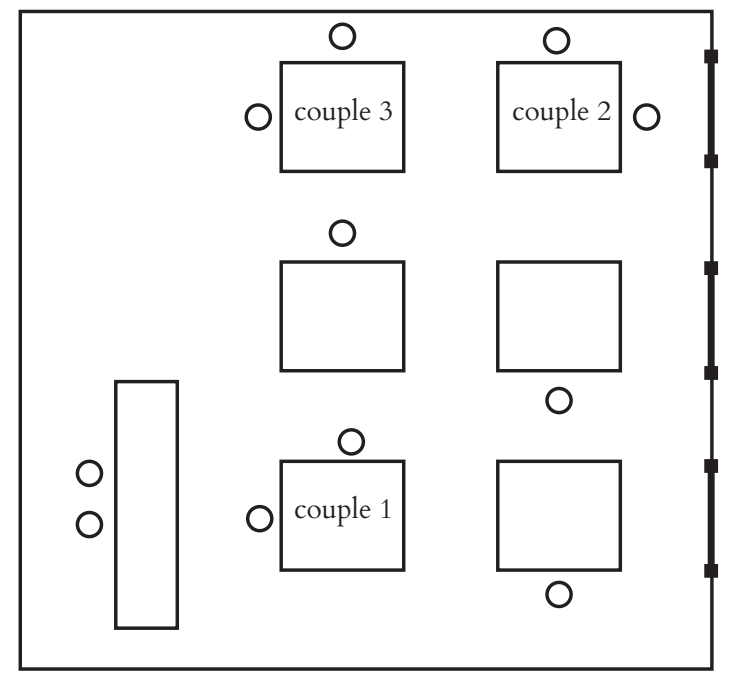


Clarifying our terminology: under standard assumptions (e.g., HEIM; KRATZER, 1998), DEMs are DPs minimally constituted by a demonstrative determiner (that, this) and a constituent headed by the noun, e.g., that couple in (1a). The nominal constituent is responsible for the "descriptive content" of the DEM; we will say that it carries additional descriptive content when the noun head is further modified, say, by an adjective, a PP, a relative clause, etc. - as in (1c).

As we intend to show, a proper understanding of the contrasts in (1) can shed some light on a basic issue concerning the semantics and the pragmatics of DEMs, namely: what is the role of the descriptive content of a DEM in the identification of its referent? We will approach the issue under a more technical formulation: how does the contextual indexing of a DEM interact with its descriptive content?

We take contextual indexing to be the component in the interpretation of deictic elements responsible for encoding deixis - that is, the relation between the expression and elements of the speech situation (the "indices") necessary for an adequate interpretation of that expression. Here, we consider two views of the contextual indexing of demonstratives. The first one claims that indices of demonstratives semantically correspond to individuals picked up by the demonstrations in the relevant speech situation, a view shared by a number of authors, including Kaplan (1989), King (2001), Nunberg (1993, 2004), Elbourne (2008), among others. The second view we will consider - actually, the one we adopt and discuss in more depth here - was proposed by Wolter (2006): for her, the indices of demonstratives are subsituations of the general speech situation. We will argue that deictic uses of DEMs licensed by additional descriptive content that is, cases like (1c) above - strongly support Wolter's theory.

Wolter herself does not discuss the role of additional descriptive content in deictic uses of demonstratives in detail. But she does discuss another use of DEMs in which additional descriptive content has a similar licensing role, namely what she calls "descriptive uses" (see section 2 below). In her analysis, she resorts to an idea that Dayal (1998) proposed to account for subtrigged any, namely, additional descriptive content introduces a "modally independent situation". Though this seems well motivated for cases discussed by Wolter, we show here that the idea cannot be extended to all cases of deictic uses of DEMs. Still, we argue that even the cases not covered in this way can be accounted for naturally under Wolter's approach with one simple additional hypothesis deixis can be "imprecise".

This paper is organized as follows: in section 2 we provide the theoretical background for the discussion, focusing on theories of demonstrative indexing; in section 3 we discuss the way Wolter accounts for the licensing role of additional descriptive content in the use of DEMs; this gives us occasion to present our main addition to Wolter's analysis - the hypothesis that situation 
L. RoeHring

TeIXIERA \& S. DE

M. Menuzzi

Understanding

the interaction

between

demonstrative

deixis and

descriptive content

indexing may be "imprecise", that is, indeterminate; this plays an important role in our analysis, explaining both "attributive-like" uses of DEMs and, crucially, deictic uses licensed by additional descriptive content; in section 4 we turn back to such cases and we show how Wolter's approach, under our interpretation, is capable of dealing with them - even in cases where additional descriptive content does not introduce a "modally independent situation"; we think some of these cases indicate the deictic component of demonstratives must refer to situations rather than to individuals; section 5 is a brief recap.

\section{The theoretical issue}

Though varying widely in implementation, many current theories of demonstratives encode the idea that contextual indexing should have some component that corresponds to the individual pointed at in the speech situation. This is the issue we want to contribute to here: whether demonstrative indexing necessarily corresponds to individuals, or to some other logical element - in particular, situations. Theories of demonstrative indexing based on individualvalued indices include not only Kaplan's (1989) theory of "direct reference", but also many other recent proposals. ${ }^{1}$ Consider an utterance like (2) below from the perspective of some such theories (see Teixeira and Menuzzi (2015a), Teixeira (2017), for further references):

$$
\text { That woman [pointing] was my colleague at high school. }
$$

Under the analysis proposed by King (2001), demonstrative determiners have the semantics in (3a) below, in which " $\mathrm{b}$ " is the demonstrative index: the variable whose value is assigned by the context and corresponds to "object of the perceptual intention", that is, the object picked up by the speaker's demonstration (cf. KING, 2001, p.43 and ff.). ${ }^{2}$ Given the semantics in (3a), the utterance in (2) above would be interpreted as in (3b):

\footnotetext{
1 In Kaplan's early paper, demonstrations are “[...] typically, though not invariably, a (visual) presentation of a local object discriminated by a pointing" (1989a, p. 753). Wolter (2006, p. 177), in turn, says that "demonstrations establish non-default situations". So, when restricted enough, situations may be pragmatically "equivalent" to individuals in that they happen to determine a piece of the world roughly circumscribed by an individual. Still, such situations are not logically "equivalent" to individuals, if the semantics adopted distinguishes the two sets of primitive entities. As we said and as will become clear, in this paper we argue for Wolter's approach. For further discussion on demonstrations, see Teixeira and Menuzzi (2015a).

2 Being the object picked up by the demonstration, it is b that will be further constrained by the "spatial constraint" on the demonstrative deixis - that is, b is the element that must be "distant from the speaker" in order to the use of that (as opposed to this) to be successful.
}

Revista Letras,

Curitiba, UFPR,

n. 96, pp.509-529,

jul./dez. 2017.

ISSN 2236-0999

(versão eletrônica) 

identical to $b$ are uniquelyjointly instantiated in $\mathrm{w}$ and $\mathrm{t}$ in an object $\mathrm{x}$, and $\mathrm{x}$ has $\mathrm{Q}$ ]

b. $\quad[[(2)]]=$ The property of being woman and the property of being identical to $b$ are uniquely jointly instantiated in $\mathrm{w}$ and $\mathrm{t}$ in an object $\mathrm{x}$,and $\mathrm{x}$ has the property of being the speaker's colleague at high school.

Clearly, the contextual variable " $b$ " in (3a) is the component in King's analysis that implements the idea that demonstrative indices refer to individuals. Note that, under the above view, either the demonstrative index, or the descriptive content of the DEM, will be somehow redundant, as discussed by King himself: besides pointing to the individual - which is a unique identification -, (3b) additionally encodes that "the property of being a woman" must be "uniquely instantiated" in the context by an object. That is, only one individual must satisfy the condition "being a woman" in the relevant context (encoded by indices " $w$ " and " $t$ "), and this quite independently of the unique identification coded by the index "b". Of course, redundancy is not a problem in itself if empirically justified, but still a theory that avoids redundancy is to be preferred conceptually (especially when empirical coverage is comparable). ${ }^{3}$

Now, let us consider a very different analysis of demonstratives, a more complex one - in particular, with respect to indexing. It is Elbourne (2008)'s, intended to be a formal implementation of the various suggestions made by $514 \quad$ Nunberg (1993).

According to Nunberg, many elements intervene in the interpretation of deictic expressions. First, he argues the index - the element contextually picked up by deixis (for demonstratives, the element pointed at) - must be distinguished from the denotation of deictic expressions. For example, in the case of the 1st person plural pronoun we, the index is the speaker, that is, the same index of pronoun $I$, the form for 1st person singular; but of course the denotations of these two pronouns are different (NUNBERG, 1993, p. 8).

Nunberg further claims that the relation between the index and the denotation has two components: the relation properly speaking, and a "classificatory" component. In the case of the pronoun we, the relation between the index (the speaker) and the denotation (a group of individuals) is "inclusion". Nunberg's "classificatory" component is the set of additional restrictions the deictic expression may impose on its denotation: in the case of $w e$, the denotation

3 King argues that the referred redundancy is justified because there are less central cases in which the two components are not redundant. This would be the case of some "no demonstration, no speaker intention" uses in which demonstrative descriptions are not interchangeable with definite descriptions (cf. King 2001, p. 68 and ff.). We will not be able to consider such cases here in detail, but for some discussion on "no demonstration, no speaker intention" uses, see section 3 below; on the "redundancy" of descriptive content, see also fn.10 here. 
L. RoEHring

TeIXIERA \& S. DE

M. MeNuZZI

Understanding

the interaction

between

demonstrative

deixis and

descriptive content

is plural, and the individuals are animate. (On Nunberg's analysis of we, see Nunberg (1993), p. 8-9; also Elbourne (2008), p. 13-14).

For Nunberg, with demonstratives not only the index is given by the context, but also its relation with the denotation. ${ }^{4}$ This can be seen in Elbourne's formalization in (4a) below, where: "x" corresponds to the index (the individual picked up by the demonstration); " $z$ " corresponds to the denotation (the unique individual denoted by the DEM); and " $\mathrm{R}$ " is the relation between " $\mathrm{x}$ " and " $\mathrm{z}$ " (cf. ELBOURNE, 2008, p. 24). Given the semantics in (4a), the sentence in (2) gets the interpretation in $(4 \mathrm{~b})$ below.

(4) a. $\quad\left[\left[\left[_{\mathrm{DP}}[[\right.\right.\right.$ that $\left.\left.\left.\mathrm{x}] \mathrm{R}] \mathrm{P}_{\mathrm{NP}}\right]\right]\right]=\lambda \mathrm{x} \cdot \lambda \mathrm{R} \cdot \lambda \mathrm{P} \cdot \lambda \mathrm{s} \cdot \mathrm{zz}[\mathrm{R}(\mathrm{x}, \mathrm{z})(\mathrm{s}) \&$ $\mathrm{P}(\mathrm{z})(\mathrm{s}) \&$ distant-from $(x$, speaker $)(\mathrm{s})]$

b. $\quad[[(2)]]=\lambda x \cdot \lambda s \cdot z[z=x$ in $s$

$\& z$ is a woman in $s$

$\& \mathrm{x}$ is distant from speaker in $\mathrm{s}]$.

$z$ was a colleague of the speaker in $\mathrm{s}$.

Here again we have a theory - in particular, in Elbourne's implementation - in which demonstrative indexing incorporates a particular element referring to an individual, namely the variable " $\mathrm{x}$ ", which is assigned as a contextual value to the individual picked up by the demonstration; and this individual is identical to the unique individual denoted by the DEM (in the case of a referential use; but see fn. 3 above). And again we see that either the relevant indexical element, "x", or the descriptive content, is somehow redundant: again the individual (uniquely) pointed at must be identical to an individual that uniquely satisfy the DEM's descriptive content in the context, the contextual restriction being encoded by index situation variable $s$.

Thus, a number of current analyses of demonstratives incorporate the claim that demonstrative indexing must refer to an individual in some way. And, at the same time, they appear to incorporate some redundancy in that both demonstrative indexing and descriptive content have an identificational role: demonstrative indexing singles out a unique individual by means of a demonstration or some other way of expressing the speaker's "perceptual 4 Nunberg's proposal is based on what he calls "descriptive uses" of demonstratives, illustrated in (i), in which "he" does not refer to Francisco I, but to individuals who have been Popes:

(i) [Pointing to Francisco I:] He used to be Italian.

In (i) the index is Francisco I, the denotation is "individuals who have been Popes", and the relation is "individuals who have had Francisco I's job in the past". For Nunberg, such cases indicate that the relation between the index and the denotation depends on contextual information. In Elbourne's formalization, the relation is part of the compositional semantics of the demonstrative; hence it is present in referential uses of DEMs as well - as in (2), where the index and the denotation seem to coincide. Of course, this is a problem which Elbourne tries to solve claiming that, as a default, this "contextual relation" is identity, as in the interpretation

Revista Letras, in (4b). We will not be able to discuss this aspect of Elbourne (2008)'s implementation here.

Curitiba, UFPR,

n. 96, pp.509-529,

jul./dez. 2017.

ISSN 2236-0999

(versão eletrônica) 
intention"; and uniqueness is required to hold of the DEM's descriptive content in a particular context.

Now, a very different proposal has been put forward by Lynsey Wolter in her PhD dissertation (WOLTER, 2016). Her basic idea is to take advantage of the fact that, since Kratzer (1989), it is generally assumed that expressions can be interpreted relative to situations - as, indeed, assumed by Elbourne in $(4 \mathrm{a}, \mathrm{b})$ above. Of course, situation indices already refer to the context relative to which an expression must be interpreted. So, Wolter's proposal for demonstratives is that this indexical element allows us to dispense with the index corresponding to the individual pointed at in deictic uses.

Wolter's theory to DEMs and definite descriptions is based on situation semantics of Kratzer (1989) and according to it all predicates (NPs and VPs) have a situation argument. Technically, Wolter's basic innovation lies in the distinction she introduces in the set of situations: (a) definite descriptions (and non-modalized predicates) are interpreted relative to the "default" speech situation $\left(\mathrm{s}_{0}\right) ; s_{0}$ is the maximal discourse situation; (b) DEMs are interpreted relative to "non-default" situations $\left(\mathrm{s}_{1}, \mathrm{~s}_{2}, \ldots\right)$, which are "subsituations" or a proper subset $\left(s_{n}\right.$ $\subset s_{0}$ ) of the default situation. Given this distinction, Wolter proposes a semantics formalization like in (5a) below for demonstrative determiners; utterance (2) now gets an interpretation like in (5b):

$\left[\left[\left[_{\mathrm{DP}}\left[\right.\right.\right.\right.$ that $\left.\left.\left.\left[{ }_{\mathrm{NP}} \mathrm{P}\right]\right]\right]\right]=\lambda \mathrm{s}_{\mathrm{n}} \cdot \lambda \mathrm{P} \cdot \mathrm{x}\left[\mathrm{P}(\mathrm{x})\left(\mathrm{s}_{\mathrm{n}}\right) \& \operatorname{distant}-\operatorname{from}(\mathrm{x}\right.$, speaker) $\left.\left(s_{n}\right)\right]$

b. $\quad[[(2)]]=\lambda s_{n} \cdot 1 x\left[x\right.$ is a woman in $s_{n} \& x$ is distant from speaker in $\left.\mathrm{s}_{\mathrm{n}}\right]$.

$\mathrm{x}$ was a colleague of the speaker in $\mathrm{s}_{0}$

Under this analysis, (2) can be true if the presupposition introduced by the demonstrative description is satisfied: if there is a particular subsituation of the speech situation such that there is a unique woman in that subsituation and she is distant from the speaker.

Now the crucial difference between Wolter's theory and the previous ones is that Wolter's does not have any "referential index" - an index corresponding directly to the individual pointed at. The only index in (2b) is the subsituation index - and the demonstration is a way of indicating this subsituation. Crucially: the referent is identified by being the unique individual satisfying the descriptive content in that subsituation. (We note, in passim, that the interpretation of predicates relative to situations, or worlds, is independently required in most truth-conditional approaches; see Wolter (2006) and Teixeira (2017) for discussion.)

Of course, under this view there is no redundancy between the indexical component of a DEM and its descriptive content: indexing identifies 
L. RoEHRING

Teixiera \& S. DE

M. Menuzzi

Understanding

the interaction

between

demonstrative

deixis and

descriptive content

the subsituation in which the compositional meaning of the DEM must be computed; and the descriptive content is the compositional means, with unicity presupposition, to compute the denotation; both together identify an unique referent in a particular situation picked by the demonstration, with no redundancy. In this sense, Wolter's approach is conceptually more interesting than theories that encode reference to an individual by indexing and, at the same time, require uniqueness with respect to the descriptive content.

Beyond conceptual considerations, the question to be answered is empirical: is there any evidence showing that referent identification does depend on the interaction of the descriptive content with unicity and situation indexing?

Moreover, Wolter assumes "non-default situations" - that is, subsituations of the speech situation - must be themselves identified by "pragmatic means" - either a demonstration or "contextual salience" (see Wolter (2006), Teixeira and Menuzzi (2015a), for discussion). But this is precisely the problem with the examples that interest us here, namely cases like (1c) above: in (1c) the deictic use of a DEM is successful without any apparent means of indicating the relevant subsituation - be it a demonstration or contextual salience. So, a second question to be answered is: how can the referent be identified in (1c) if indexing does not indicate the subsituation unambiguously? What is the role of additional descriptive content in these cases?

\section{Additional descriptive content and "modally independent situations"}

Let us turn to the issue of the role of additional descriptive content in cases like (1c). As we already mentioned, Wolter herself does not discuss such cases in her dissertation, but she does consider the role of additional descriptive content in another use of DEMs, namely, what she calls "descriptive uses". Here we will call them "no demonstration, no speaker intention" (NDNS) uses, following King (2001), in order to avoid confusion with Nunberg (1993)'s "descriptive uses" (see fn. 4 above).

Specifically, in NDNS cases DEMs are interpreted in a way similar to attributive definite descriptions (see King (2001), Wolter (2006), for further discussion), as shown in (6a) below; the absence of the relevant reading in (6b) shows that NDNS uses of DEMs require some additional descriptive content, such as the relative clause in (6a):

(6) a. That/The student [who scored one hundred on the exam] is a genius. "Whoever is the student who scored one hundred on the exam, he is a genius"

Revista Letras,

Curitiba, UFPR, n. 96, pp.509-529,

jul./dez. 2017. ISSN 2236-0999 (versão eletrônica) 
b. That student is a genius.

"\#Whoever is the student, he is a genius."

But it is not any sort of additional descriptive content that licenses NDNS readings: Wolter observes that such readings seem to present the same constraints as the so-called "subtrigged any", discussed in Dayal (1998; see also Dayal (2004)). Consider any first: the contrast between (7a) and (7b) shows that it can be licensed - hence, "subtrigged" - by additional descriptive content; and the contrast between (7b) and (7c) shows that it is licensed by some modifiers like relative clauses and other adjuncts, but not by arguments of the head noun:

(7) a. ?? John bought any picture.

b. John bought any picture [that was on sale in the gallery].

c. ?? John bought any picture [of Queen Elizabeth].

Crucially, Wolter points out NDNS uses of DEMs show a similar pattern: a DEM without some additional modifier cannot be interpreted as NDNS expression, as in (8a) below (also in (6b) above); it does have such an interpretation if the modifiers is a relative clause, as in (8b) below (also in (6a)); but, just like subtrigged any, the NDNS reading is also excluded if the modifier is an argument of the head noun, as in (8c):

(8) a. [That inventor] is a genius. (\#NDNS; ${ }^{\text {OK }}$ anaphora/deixis)

b. [That inventor who created the computer] is a genius. ( ${ }^{\mathrm{OK}} \mathrm{NDNS}$ )

c. [That inventor of the computer] is a genius. (\#NDNS; ${ }^{\mathrm{OK}}$ anaphora/ deixis)

As Dayal and Wolter show, it is not only relative clauses, but a class of adjuncts, that licenses both subtrigged any and NDNS uses of DEMs. Thus, the question is: why only adjuncts?

In Dayal's analysis of subtrigged any, the crucial property of adjuncts is that they are "modally independent", in particular because - as she argues they have temporal independence with respect to the head nouns. Technically, she takes them to introduce a situation which properly constrains the universal quantification of any, as in (9b) below; absence of such a situation results in an utterance like $(9 \mathrm{a})$, which is false:

5 The reading is possible, though, if the DEM is anaphoric to a DP with a generic-like reading:

(i) The/Any student who scored one hundred on the exam must really know all about integrals. That student surely is a genius. (= "Whoever is the student who scored etc., he is a genius.") 
L. RoEHRing

Teixiera \& S. DE

M. MenuzZI

Understanding

the interaction

between

demonstrative

deixis and

descriptive content
(9)
a. $\quad[[(7 \mathrm{a})]]=$
b. $\quad[[(7 b)]]=$

$\forall \mathrm{s}, \mathrm{x}[\operatorname{picture}(\mathrm{x}, \mathrm{s})] . \exists \mathrm{s}^{\prime}\left[\mathrm{s}<\mathrm{s}^{\prime} \& \operatorname{buy}\left(\mathrm{j}, \mathrm{x}, \mathrm{s}^{\prime}\right)\right]$

$\forall \mathrm{s}, \mathrm{x}$ [picture $(\mathrm{x}, \mathrm{s}) \& \exists \mathrm{s}^{\prime}\left[\mathrm{s}<\mathrm{s}^{\prime} \&\right.$ on-sale $\left(\mathrm{x}, \mathrm{s}^{\prime}\right) \&$ past $\left.\left.\left(s^{\prime}\right)\right]\right]$.

$\exists s^{\prime \prime}\left[s<s " \& \operatorname{buy}(j, x, s ") \& \operatorname{past}\left(s^{\prime \prime}\right)\right]$

According to the analysis in (9a), (7a) is interpreted as meaning something like: for all situation $\mathrm{s}$ and individual $\mathrm{x}$ such that $\mathrm{x}$ is a picture in $\mathrm{s}$, there is a situation s' that extends s and John bought $\mathrm{x}$ in s'. Given this analysis, Dayal (1998, p. 453) suggests the following account for the marginality of sentences like (7a):

[...] there will be many situations that will render the statement false, for example, all those [picture] situations that do not overlap with John's existence. There is something infelicitous in making a statement that is doomed to be false. One way to formalize this intuition about unacceptability of any in episodic sentences $[\ldots]$ is to treat it as a case of presupposition failure. In using an any phrase, the speaker chooses to talk about all situations, but in making an assertion about a bounded time interval, she must focus on a restricted set of situations. This results in an irresolvable conflict of presuppositions.

That is, for Dayal, by using any the speaker incurs in a conflict of presuppositions, which she takes to amount to a presupposition failure - hence, the sentence's pragmatic infelicity. ${ }^{6}$

Consider (9b) now. According to it, (7b) means: for all $\mathrm{x}$ and $\mathrm{s},(\mathrm{a})$ if $\mathrm{x}$ is a picture in $s$ and there is a situation s' (in the past) in which $s$ is contained and $x$ is on sale in s', then the truth of (7b) can be computed; and (b) (7b) is true iff there is another situation s" in the past in which s is contained and John bought $\mathrm{x}$ in s". According to Dayal (2004, p. 223), under this interpretation, a sentences like (7b) restricts the domain of quantification to those possible individuals and situations that also fulfill the property in the relative clause (including the property of being in the temporal interval denoted by the tense specification of the clause). Thanks to this restriction, utterance (7b) is not about all situations and pictures, but only about situations and pictures such that the situation is contained in some past situation and the picture was on sale in that past situation.

As for the fact that arguments do not license subtrigged any, Dayal's proposal is simple: arguments are not independent predicates, let alone "modally independent" from the head noun. Actually, being arguments of the function

6 A reviewer finds it implausible that the marginality of sentences like (7a) be due to pragmatic infelicity of the sort proposed by Dayal. He/she observes that utterances can be unlikely to be true, and they can even be contradictory, without being "unacceptable". Dayal herself discusses similar objections, though arguing that her analysis can be maintained (see Dayal (1998), p.253, fn.5).
Revista Letras,

Curitiba, UfPr, n. 96, pp.509-529, jul./dez. 2017. ISSN 2236-0999 (versão eletrônica) 
denoted by the noun, they must belong to the same situation as that relative to which the predicate is interpreted. That is, formally - unlike, say, a relative clause - an argument is in a sense "part of" the nominal predicate and do not introduce an independent situation. This is what we represent in (9c) below:

$$
\text { c. } \quad[[(7 c)]]=\forall s, x[\text { picture-of-QE }(x, s)] . \exists s^{\prime}\left[s^{\prime}<s^{\prime} \& \operatorname{buy}\left(j, x, s^{\prime}\right)\right]
$$

It is easy to see that, under the assumptions above, (7c) is unacceptable because the universal quantification expressed by any is improperly restricted, just like (7a). Hence, an utterance like (7c) is pragmatically anomalous, too.

Of course, being the case that NDNS uses of DEMs show the same restriction, there should be a way of adapting Dayal's analysis to DEMs. Indeed, this can be done under Wolter's theory of DEMs with a very simple hypothesis. Here is our proposal: non-default situations - the subsituations of the speech situation referred to by the indexical component of demonstratives - can be indeterminate, that is, their limits may not precisely known or indicated by the speaker. Let us notationally represent such indeterminate non-default situations by using "s?", instead of $s_{1}, s_{2}$, etc . This additional possibility for non-default situations correctly predicts the attributive-like properties of NDNS readings of DEMs. To see this, consider how the analyses for $(8 \mathrm{a}, \mathrm{b}, \mathrm{c})$ above would look like: ${ }^{8}$

$$
\begin{array}{r}
\text { a. } \left.\quad[(8 \mathrm{a})]]=\mathrm{xx} \text { [inventor }\left(\mathrm{x}, \mathrm{s}_{\mathrm{?}}\right) \& \text { distant-from }\left(\mathrm{x}, \text { speaker, } \mathrm{s}_{\mathrm{z}}\right)\right] . \\
{\left[\text { genius }\left(\mathrm{x}, \mathrm{s}_{0}\right)\right]}
\end{array}
$$

$7 \quad$ A reviewer notes that not only non-default situations can be indeterminate, but also default situations, which is of course true - an observation that is fully compatible with our analysis. Here is an example: suppose a professor says to another, in a party with students, the utterance "I hope the students are not hearing what you're saying". To which students is he referring? Pragmatically, it is likely that he is referring to students who are spatially close - and even so there will be indeterminacy about which students are covered by the "default" situation.

Another reviewer questions our notation (subscripting situation variables with "?"), asking how it should be interpreted logically or semantically. We are not yet in the position to advance a more definite interpretation of the text's notation. It might just be the boundaries between situations may not be totally determined. Actually, this possibility is sometimes suggested by Kratzer, e.g., when she says: "The parts of a world are its situations. Since worlds are parts of themselves, they are also situations. They are maximal situations, situations that are not part of other situations" (1989, p. 611). Technically, it might be that speaker and listener come to agree that, under certain circumstance, the discrimination among situations does not need to go beyond a particular limit. In such circumstances, the referred situation might be, say, s41, s42 or s43 - but it is not relevant to distinguish among them.

$8 \quad$ Wolter $(2006,2007)$ 's own implementation of Dayal's analysis here suggested is very likely to be incorrect: it results in an interpretation just like any simple deictic use of DEMs - in which the relevant subsituation is determinate. So, truth conditions are just the same as those of a deictic use, and do not explain the attributive-like properties of the NDNS DEMs.

A further note on the pragmatics of NDNS DEMs: this reading usually implies that the referent is unknown by the speaker, which might explain why only the "distal" demonstrative is compatible with it. The utterance below, referring to an unknown inventor, is possible only if the DEM is anaphoric: 
L. RoEHRing

TeIXIERA \& S. DE

M. MenuzZI

Understanding

the interaction

between

demonstrative

deixis and

descriptive content

b. $\quad[[(8 b)]]=1 \mathrm{x}$ [inventor $\left(\mathrm{x}, \mathrm{s}_{\mathrm{?}}\right) \&$ distant-from $\left(\mathrm{x}\right.$, speaker, $\left.\mathrm{s}_{\mathrm{z}}\right) \&$ $\exists \mathrm{s}^{\prime}\left[\mathrm{s}_{?}<\mathrm{s}^{\prime} \&\right.$ create-computers $\left.\left.\left.\left(\mathrm{x}, \mathrm{s}^{\prime}\right) \& \operatorname{past}\left(\mathrm{s}^{\prime}\right)\right]\right]\right]$. [genius $\left.\left(\mathrm{x}, \mathrm{s}_{0}\right)\right]$

c. $\quad[[(8 c)]]=1 \mathrm{x}$ [inventor-of-computers $\left(\mathrm{x}, \mathrm{s}_{\mathrm{z}}\right) \&$ distant-from $\left(\mathrm{x}\right.$, speaker, $\left.\left.\mathrm{s}_{\mathrm{z}}\right)\right]$. [genius $\left.\left(\mathrm{x}, \mathrm{s}_{0}\right)\right]$

Clearly, (10a) indicates why a DEM, with no restriction on the indeterminate subsituation, cannot be felicitous: since the subsituation is indeterminate, there is no way of verifying which subsituation the speaker is talking about - hence, we can not verify the truth conditions of the sentence (8a). The case of $(10 c) /(8 c)$ is similar: if arguments are just part of the situation introduced by their predicates, that is, if they do not introduce a situation on their own, they do not constrain the situation introduced by their predicates and, again, there is no way of verifying which subsituation the speaker is talking about.

But consider (10b) now. Under this analysis, (8b) means something like: if there is a unique $\mathrm{x}$ such that $\mathrm{x}$ is an inventor in the speech subsituation $\mathrm{s}$, and is distant from the speaker in $s_{\text {? }}$, and there is a situation s' such that $s_{?}$ is part of $s^{\prime}$ and $x$ created computers in s', then ( $8 b$ ) is true if and only if $x$ is a genius in the default situation $\mathrm{s}_{0}$. Now, the situation introduced by the "modally independent" modifier does provide the means for verifying the truth conditions of the sentence: the speaker did not specify which non-default situation s, he is talking about - hence, in a sense, it is "distant from" him; but he did specify that there is a situation s' of which situation $s$, is part of $-s^{\prime}$ must be a situation such that $\mathrm{x}$ is the unique individual who created a computer in it. Of course this properly restricts the set of situations that must be looked for.

The analysis just sketched explains why DEMs can have the NDNS reading, and actually provides a very intuitive description of the truth conditions of such readings. That is: under the assumption that non-default situations can be indeterminate, Wolter's theory of demonstratives is able to explain the attributive-like use of DEMs.

Crucially, the line of explanation just proposed for NDNS DEMs does seem to explain some of cases in which deictic DEMs require no pointing to be successful in specifying the relevant non-default situation. Let us reconsider the contrast between (1b) and (1c) above. Under the assumptions we have just made, these utterances in (1a), (1b) and (1c) would get the following interpretations $(x$ is a plural individual in (11) below):

(11) a. $[[(1 \mathrm{a})]]=\mathrm{x} \quad\left[\operatorname{couple}\left(\mathrm{x}, \mathrm{s}_{4}\right) \&\right.$ distant-from $\left(\mathrm{x}\right.$, speaker, $\left.\left.\mathrm{s}_{4}\right)\right]$. [wants-a-cesar-sallad $\left(\mathrm{x}, \mathrm{s}_{0}\right)$ ]

Revista Letras,

Curitiba, UFPR, n. 96, pp.509-529,

jul./dez. 2017. ISSN 2236-0999 (versão eletrônica) 

b. $\quad[[(1 b)]]=1 \mathrm{x} \quad\left[\operatorname{couple}\left(\mathrm{x}, \mathrm{s}_{\mathrm{?}}\right) \&\right.$ distant-from $\left(\mathrm{x}\right.$, speaker, $\left.\left.\mathrm{s}_{\mathrm{?}}\right)\right]$. [wants-a-cesar-sallad $\left.\left(\mathrm{x}, \mathrm{s}_{0}\right)\right]$
c. $[[(1 \mathrm{c})]]=1 \mathrm{x} \quad\left[\operatorname{couple}\left(\mathrm{x}, \mathrm{s}_{\mathrm{z}}\right) \&\right.$ distant-from $\left(\mathrm{x}\right.$, speaker, $\left.\mathrm{s}_{\mathrm{z}}\right) \&$ $\exists \mathrm{s}^{\prime}\left[\mathrm{s}_{?}<\mathrm{s}^{\prime} \&\right.$ next-to-the-window $\left.\left.\left.\left(\mathrm{x}, \mathrm{s}_{0}\right)\right]\right]\right]$.
[wants-a-cesar-sallad(x, $\left.\mathrm{s}_{0}\right)$ ]

In (11a), we just see how Wolter's analysis accounts for simple deictic uses: a subsituation $\mathrm{s}_{4}$, such that there is only one couple in it is picked up by pointing, and the utterance is evaluated as usual. (11b) shows why lack of pointing makes the same sentence fail: now the relevant subsituation is indeterminate, since no specific subsituation of the speech situation is picked up by pointing; but other subsituations in the relevant speech situation would satisfy the uniqueness condition (they would be subsituations in which there is a unique couple), hence the utterance fails because its truth cannot be evaluated'

Finally, (11c) shows why the additional modifier turns the utterance acceptable: the subsituation intended by the speaker to be identified by the hearer is, still, indeterminate; but now the additional modifier tells the hearer that, besides being distant from the speaker, the subsituation must be part of another situation (in the speech situation) in which the referent to be identified is next to a window. Well, there is now a subsituation in which the predicate "couple" satisfy uniqueness - hence, the sentence is interpretable and, moreover, felicitous in referring to the relevant couple.

In short: we started by looking at the way additional descriptive content can license the NDNS use of DEMs: according to Wolter, following Dayal's account of subtrigged any, it is because adjuncts may introduce "modally independent" situations. In order to implement this idea, we proposed that such "modally independent" situations allow an utterance to be interpreted even with an indeterminate subsituation of the speech situation. And we have, now, shown that these assumptions can explain - with no further ad hoc assumptions - cases in which additional descriptive content licenses deictic uses of DEMs with no demonstrations, like (1c).

We take this combined explanation of both cases as a strong argument for Wolter's theory of demonstrative indexing - and against theories which do not appeal to situation-based indexing, such as the direct reference theory. But the argument can be made stronger.

\footnotetext{
9 An anonymous reviewer pointed out that we could think about the selection of subsituations in cases such as (1c)/(11c) as picking up the set of all compatibles subsituations, for example, in cases where there is more then one couple next to the window. So, we could have a set of all subsituations where there is a couple close to a window. Teixeira (2017) discusses similar case affirming that if the descriptive content is not enough to ensure unicity, the speaker adds more descriptive material until uniqueness will be satisfied. Hence, we can say that each one of these elements of restriction will reduce the domain until the uniqueness will be satisfied.
} 
L. RoEHring

TEIXIERA \& S. DE

M. Menuzzi

Understanding

the interaction

between

demonstrative

deixis and

descriptive content

\section{Additional descriptive content with no "modally independent situation"}

Though the account presented in the previous section does seem to explain the role of additional descriptive content in some deictic uses of DEMs with no pointings, it cannot explain all cases. Indeed, the account relies on an analogy with NDNS uses, which happen to be licensed only by adjuncts - and only adjuncts can be "modally independent". But here is a crucial difference between NDNS and deictic uses: the additional descriptive content contributed by an argument can actually license a deictic use without any pointing, as in the context in (12c) below (to be compared with the unavailability of a NDNS reading in $(8 \mathrm{c}))$ :

(12) Context: in a scientific fair; two judges discuss the abilities of the contestants, who they are watching; one of the judges whispers to the other, about the inventor of computer 1 :
a. [pointing to him:]
That inventor is a genius.
b. [with no pointing:]
\#That inventor is a genius.
c. [with no pointing:]
That inventor of computers is a genius.

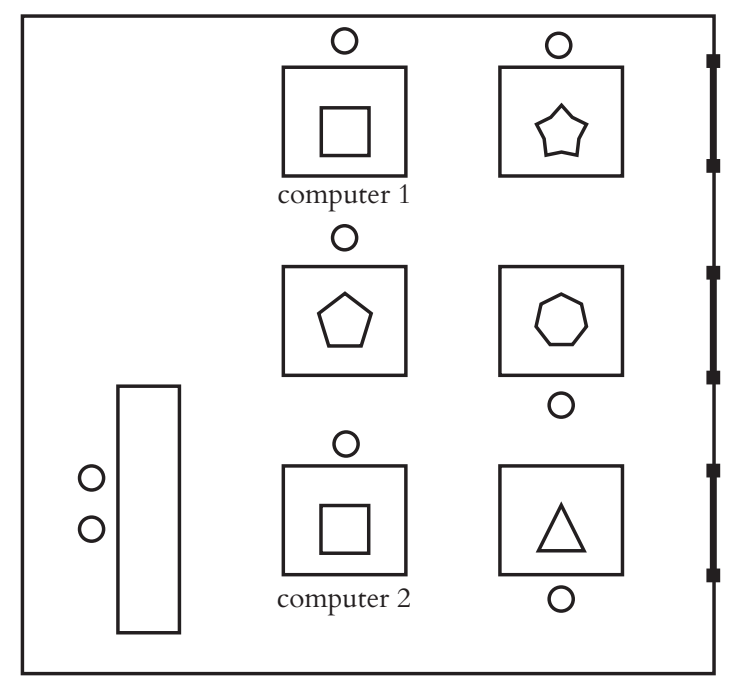

Of course, if the contrast between adjuncts and arguments in licensing subtrigged any and NDNS uses of DEMS, as in (7) and (8), is correct, then the analysis we have given for (1c) - cf. (11c) above - cannot explain (12c): in (12c) the additional descriptive content of the DEM comes from an argument, and arguments do not introduce "modally independent" situations according to Dayal $(1998,2004)$ and Wolter (2006). Therefore, (i) the adjunct-only restriction does

Revista Letras,

Curitiba, UFPR, n. 96, pp.509-529,

jul./dez. 2017. ISSN 2236-0999 (versão eletrônica) 
not hold to DEMs and (ii) cases like (12c) indicate that descriptive content can be sufficient by itself to license a deictic DEM - that is, independently of introducing an additional situation, and independently other "pragmatic means" such as demonstrations or contextual salience of the subsituation.

But how can that be? Under the theory we have been developing here, based on Wolter's situation indexing, the answer is surprisingly simple: if the descriptive content of the DEM (i) can be compositionally computed; (ii) it is not restricted to adjuncts; and (iii) by itself it allows the identification of the proper speech subsituation in which unicity holds, then it does not need any further means, like demonstrations or other pragmatic information. To see this, let us take a look at the interpretations that the utterances in (12) would get in our analysis:

$$
\begin{aligned}
& \text { a. } \left.[[(12 \mathrm{a})]]=1 \mathrm{x} \text { [inventor }\left(\mathrm{x}, \mathrm{s}_{3}\right) \& \text { distant-from }\left(\mathrm{x}, \text { speaker, } \mathrm{s}_{3}\right)\right] \text {. } \\
& \text { genius }\left(\mathrm{x}, \mathrm{s}_{0}\right) \\
& \text { b. } \left.\quad[[(12 b)]]=1 \mathrm{x} \quad \text { inventor }\left(\mathrm{x}, \mathrm{s}_{\mathrm{?}}\right) \& \text { distant-from }\left(\mathrm{x}, \text { speaker, } \mathrm{s}_{\mathrm{z}}\right)\right] \text {. } \\
& \text { genius }\left(x, s_{0}\right) \\
& \text { c. }[[(12 c)]]=1 \mathrm{x} \text { [inventor-of-computers }\left(\mathrm{x}, \mathrm{s}_{\mathrm{?}}\right) \& \text { distant-from }(\mathrm{x} \text {, } \\
& \text { speaker, } \left.\left.s_{?}\right)\right] \text {. } \\
& \text { genius }\left(\mathrm{x}, \mathrm{s}_{0}\right)
\end{aligned}
$$

We believe (13a) does not require any further comment at this point. Now consider the unsuccessful (12b), where absence of pointing leads to the impossibility of referent identification: according to (13b), absence of pointing actually corresponds to an indeterminate speech subsituation; since there are other speech subsituations in context (12) in which there would be an inventor "distant from" the speaker, there is no way of identifying the specific subsituation the speaker is trying to refer to.

Finally, consider the crucial case (12c). Not only the additional descriptive content corresponding to the predicate argument does not introduce any "modally independent" situation, but the speech subsituation in which the DEM must refer is also indeterminate - since it was not identified by any pointing, nor by "contextual salience". Even so, it is possible for the hearer to work out which speech subsituation is this, for there is only one computer which is "distant from" the speaker in speech situation, namely computer 1 . That is, (12c) is clearly a case in which computing the descriptive content of a DEM compositionally is sufficient for the identification of a speech subsituation in which unicity holds even in absence of a pointing. That is, indexing may actually be indeterminate when compositional semantics can do the job, independently if the element responsible by restriction is an argument, an adjunct, or any other category.

Further cases confirm that DEMs are successful when there is an appropriate interaction between situation indexing and compositional 
L. RoeHring

Teixiera \& S. DE

M. Menuzzi

Understanding

the interaction

between

demonstrative

deixis and

descriptive content

descriptive content. In (14) below we present a case that, for us, definitely shows that demonstrative indexing refers to speech subsituations:
Context: in a parking lot:
a. [pointing to a corner:]
\# That car is mine.
b. [pointing to a corner:]
That red car is mine.
c. [no pointing:]
\# That red car is mine.

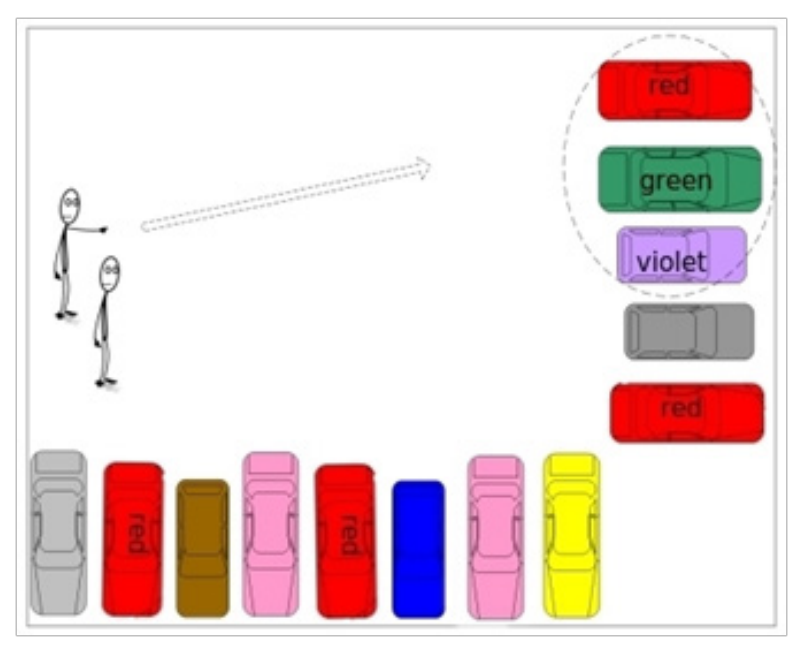

The crucial contrast is between (14a) and (14b). In (14a), pointing is picking up not a particular car, but a spatial area, in which there are three cars; that is, the subsituation is determinate, but still its identification is not enough for the DEM that car to pick up a unique car; hence, the utterance is unsuccessful. This case is adequately captured by the interpretation in (15a) below: $:^{10}$

$$
\text { a. } \begin{aligned}
{[[(14 a)]]=1 \mathrm{x} \quad } & {\left.\left[\operatorname{car}\left(\mathrm{x}, \mathrm{s}_{3}\right) \& \text { distant-from (speaker, } \mathrm{s}_{3}\right)\right] . } \\
& \text { is-mine }\left(\mathrm{x}, \mathrm{s}_{0}\right)
\end{aligned}
$$

Of course, (15a) fails because the presupposition of unicity fails.

In (14b), the case is similar to (14a) as far as indexing is concerned - the same spatial area is picked up by pointing; but now it is the additional descriptive content that allows proper identification of the car - even if indexing picks up a subsituation in which there are three cars; but only one is red! The felicity of $(14 b)$ is adequately captured by $(15 b)$ below.

\footnotetext{
10 A reviewer suggests that it is "hard to tell whether the speaker is really pointing to an spatial area or not"; the speaker might be trying to point to a specific car, but pointing might be ambiguous, or the speaker might have just failed - and additional descriptive content might help "detecting the speaker's intention". These is an interesting suggestion; but it requires either clarifying what the ambiguity would be, or demonstrating the speaker intention's failure - or the speaker's intention, anyway. None of this is required in the analysis argued for in the text.

The reviewer observes that "in some similar situations [...] the addition of a further qualification of the car (like red) is redundant" (it is possible to say "That red car" in a scene with just one car, though not with focus on red). He/she argues that "redundancy was one of the arguments used to defend [this paper's] approach, but it does not seem that it is necessarily a problem". We first note that the problem with redundancy raised in section 2 is conceptual, unrelated to the particular case in (14). Second, in the cases observed by the reviewer, both approaches - the one based on individual indexing and the one based on situation indexing - are empirically equivalent. And, third, it is precisely in cases like (14) - in which there is no redundancy - that the two approaches differ: for these, individual indexing will have to adopt something like the reviewer's suggestion in the first paragraph of this note.
}

Revista Letras,

Curitiba, UFPR,

n. 96, pp.509-529,

jul./dez. 2017.

ISSN 2236-0999

(versão eletrônica) 
$\begin{aligned} &(15) \quad \text { b. } \quad[[(14 b)]]=1 \mathrm{x} \quad {\left.\left[\operatorname{car}\left(\mathrm{x}, \mathrm{s}_{3}\right) \& \operatorname{red}\left(\mathrm{x}, \mathrm{s}_{3}\right) \& \text { distant-from (speaker, } \mathrm{s}_{3}\right)\right] . } \\ & \text { is-mine }\left(\mathrm{x}, \mathrm{s}_{0}\right)\end{aligned}$

Finally, (14c) confirms that, in (14), what is necessary is a proper interaction between indexing and descriptive content: in (14c) there is no indexing, hence the subsituation is indeterminate, as represented in (15c) below; since more than one speech subsituation in (14) is such that it would contain a unique red car "distant from" the speaker, the subsituation the speaker is referring to cannot be identified - and the utterance is infelicitous, despite the presence of additional descriptive content:

$$
\begin{aligned}
\text { c. } \quad[[(14 \mathrm{c})]]=1 \mathrm{x}\left[\operatorname{car}\left(\mathrm{x}, \mathrm{s}_{\mathrm{p}}\right) \& \operatorname{red}\left(\mathrm{x}, \mathrm{s}_{\mathrm{p}}\right) \&\right. \\
\quad
\end{aligned}
$$

As far as we can tell, (14) has never been discussed - and we cannot see how it can be accounted for if indexing does not pick up situations, but individuals.

Just to end up this discussion, we note that demonstratives in general whether DEMs or bare demonstrative determiners - are likely to be subject to the same basic principles governing the interaction between situation indexing and descriptive content - the principles we just presented. This is shown by (16) below, which reproduces the contrasts in (14), but now opposing bare demonstratives to simple DEMs; the interpretation of the utterances are given in (17):

(16) Context: A wallet, a book and a pen lie on a corner on a table. Someone tries to refer to the wallet:
a. [No pointing:]
\# That is mine.
b. [Pointing to the corner:]
\# That is mine.
c. [Pointing to the corner:] That wallet is mine.

(17) a. $[[(16 \mathrm{a})]]=1 \mathrm{x}\left[\right.$ in $\left(\mathrm{x}, \mathrm{s}_{\mathrm{p}}\right) \&$ distant-from (speaker, $\left.\left.\mathrm{s}_{\mathrm{p}}\right)\right]$. is-mine $\left(\mathrm{x}, \mathrm{s}_{0}\right)$

b. $\quad[[(16 b)]]=1 x\left[\right.$ in $\left(x, s_{7}\right) \&$ distant-from (speaker, $\left.\left.s_{7}\right)\right]$. is-mine $\left(x, s_{0}\right)$

c. $[[(16 c)]]=1 \mathrm{x}\left[\right.$ wallet $\left(\mathrm{x}, \mathrm{s}_{7}\right) \&$ distant-from (speaker, $\left.\left.\mathrm{s}_{7}\right)\right]$. is-mine

(16) shows that it is "descriptive content", and not additional descriptive content, which really matters - appropriate descriptive content will be necessary whenever indexing is not enough. (As for a situation in which indexing would be enough, imagine a context similar to (16) in which the wallet is in one corner of the table, and the book and the pen in the other.) 
L. RoEHRing

TeIXIERA \& S. DE

M. MenuZZI

Understanding

the interaction

between

demonstrative

deixis and

descriptive content

\section{Summing up}

In this paper, we have discussed the role descriptive content has in the interpretation of demonstratives, starting with DEMs. In particular, we have discussed cases in which additional descriptive content seems to dispense with demonstrations and other pragmatic means of identifying the DEMs referent. As we tried to show, such cases are crucial for understanding the way the indexical component of demonstratives interacts with descriptive content. And, if our argumentation is correct, they actually constitute strong evidence for Wolter (2006)'s theory of demonstrative indexing where DEMs refer to subsituations, as opposed to theories that codify some version of Kaplan's "direct reference" hypothesis in which DEMs refer directly to individuals. Summing up, we have shown that:

(i) there is no need for ad hoc ${ }^{11}$ assumptions if we take Wolter (2006)'s analysis seriously: the deictic component of DEMs indicate subsituations of the default situation, and not individuals; hence, accounts of demonstratives based on deixis to individuals are bound to be inadequate - as is the case of Kaplan (1989), Nunberg (1993, 2004), King (2000) and Elbourne (2008);

(ii) a crucial aspect to take into account, however, is that demonstrative deixis is sometimes imprecise about the limits of the subsituation it tries to indicate, in which case (additional) descriptive content may be required to ensure unicity;

(iii) as a subsidiary result, we have shown that "attributive-like" uses of DEMs (King's NDNS uses) can have their readings properly understood if the subsituation referred to by demonstrative is indeterminate: the interaction of this with the rest of the sentence's generic-like semantics provide a natural characterization of NDNS readings.

Revista Letras,

Curitiba, UFPR, n. 96, pp.509-529, jul./dez. 2017. ISSN 2236-0999 (versão eletrônica)
11 It is important recall that ' $\mathrm{s}$ ' is not a new kind of situation, since it is part of the set of subsituations proposed by Wolter (2006). 


\section{References}

DAYAL, V. Any as inherently modal. Linguistics and Philosophy, v. 21, p. 433476, 1998.

DAYAL, V. Licensing by modification. Ilha do Desterro, v. 47, p. 217-238, 2004.

ELBOURNE, P. D. Situations and Individuals. Cambridge, MA: MIT Press, 2005.

ELBOURNE, P. D. Demonstratives as individual concepts. Linguistics and Philosophy, v. 31, p. 409-466, 2008.

HEIM, I.; KRATZER, A. Semantics in Generative Grammar. Oxford: Blackwell, 1998.

KAPLAN, D. Demonstratives: an essay on the semantics, logic, metaphysics, and epistemology of demonstratives and other indexicals. In ALMOG, J.; PERRY, J.; WETTSTEIN, H. (Eds.), Themes from Kaplan. New York: Oxford University Press, 1989a. p. 481-563.

KAPLAN, D. Afterthoughts. In ALMOG, J.; PERRY, J.; WETTSTEIN, H. (Eds.), Themes from Kaplan. New York: Oxford University Press, 1989b. p. 564614.

KING, J. Complex Demonstratives: a quantificational account. Cambridge: MIT Press, 2001.

KRATZER, A. An investigation of the lumps of thought. Linguistics and Philosophy, v. 12, p. 607-653, 1989.

NUNBERG, G. Indexicality and deixis. Linguistics and Philosophy, v. 16, p. 1-43, 1993.

NUNBERG, G. Descriptive indexicals and indexical descriptions. In REIMER, M.; BEZUIDENHOUT, A. (Eds.). Descriptions and beyond. Oxford: Clarendon, 2004. p. 261-279.

TEIXEIRA, L. R. Os demonstrativos: uma análise semântico-pragmática baseada em situações. PhD dissertation. UFRGS, Porto Alegre (Brazil), 2017.

TEIXEIRA, L. R.; MENUZZI, S. M. Formal demonstrations with deictic demonstratives: in defense of Wolter's notion of non-default situation. ReVEL, v. 9, p. 33-61, 2015a.

TEIXEIRA, L. R.; MENUZZI, S. M. Algumas questões sobre as descrições demonstrativas dêiticas. Cadernos do IL, v. 50, p. 09-27, 2015b.

WOLTER, L. K. That's That: The semantics and pragmatics of demonstrative noun phrases. PhD dissertation. University of California, Santa Cruz, 2006. 
L. RoeHring

TeIXIERA \& S. DE

M. MenuzzI

Understanding

the interaction

between

demonstrative

deixis and

descriptive content
WOLTER, L. K. Situation variables and licensing by modification in opaque demonstratives. In PUIG-WALDMÜLlER, E. (Ed.) Proceedings of Sinn und Bedeutung 11. Barcelona: Universitat Pompeu Fabra, 2007. p. 612-625.

Submetido em: 21-03-2017

Aceito em: 26-07-2017 